BAKTIMAS

Jurnal Pengabdian pada Masyarakat
Vol. 1, No. 1, Juni 2019 eISSN2685-113x

pISSN2685-0303

\title{
Menciptakan Wirausaha Budidaya Ikan Lele dengan Sistem Bioflok
}

\author{
Muhammad Irfan Nasution, Muhammad Andi Prayogi, Jufrizen \\ Universitas Muhammadiyah Sumatera Utara \\ Jalan Kapten Mukhtar Basri No. 3 Medan \\ Email : muhammadirfan@umsu.ac.id
}

\begin{abstract}
The Community Partnership Program has the theme of making community groups become entrepreneurs of catfish farming with biofloc ponds in Desa Marindal II Kec. Patumbak, Kabupaten Deli Serdang North Sumatra Province, encourages the empowerment of community groups towards productive entrepreneurs. This PKM has a short-term program that is to increase the ability to think and improve skills. The Community Partnership Implementation Program was held for 12 months with 2 PKM Partners namely 1) Marindal II Village Community Group and Joint Farmer Group. This PKM stage includes preparation, survey and location collection, analysis of potential and problems, focus group discussions (FGD), implementation of activities, monitoring and evaluation. The method used is using participatory participation methods, community empowerment, evaluation discussions, and monitoring. The output generated by the Community Partnership Program consists of 2 units of Bioflok catfish ponds, Catfish Seeds for enhancement, increasing competitiveness, the creation of new entrepreneurs in the community, producing catfish products, increasing science and technology in society and improving community governance that produces security.
\end{abstract}

Kata kunci: Community Empowerment, Entrepreneurship, Catfish Cultivation

\begin{abstract}
Abstrak
Program Kemitraan Masyarakat (PKM) bertemakan menciptakan kelompok masyarakat menjadi wirausaha budidaya ikan lele dengan kolam bioflok di Desa Desa Marindal II Kec. Patumbak Kabupaten Deli Serdang Provinsi Sumatera Utara, bertujuan untuk pemberdayaan kelompok masyarakat menjadi wirausaha yang produktif. PKM ini memiliki program jangka pendek yaitu untuk meningkatkan kemampun berfikir dan keterampilan berusaha. Pelaksanaan Program Kemitraan Masyaraka (PKM) dilaksanakan selama 12 bulan dengan 2 Mitra PKM yaitu 1) Kelompok Masarakat Desa Marindal II dan Kelompok Tani Bersama. Tahapan PKM ini meliputi tahap persiapan, survei dan identifikasi lokasi, analisis potensi dan masalah, focuss group discussion (FGD), pelaksanaan kegiatan, monitoring dan evaluasi. Metode yang digunakan adalah dengan menggunakan metode pendekatan melalui pendekatan participatory, community empowerment, tahap evaluasi dan monitoring. Luaran yang dihasilkan PKM ini adalah 2 unit kolam ikan lele Bioflok, Benih Ikan Lele untuk Pembesaran, peningkatan daya saing, terciptanya wirausaha baru di masyarakat, menghasilkan
\end{abstract}


produk ikan lele, peningkatan ipteks di masyarakat dan perbaikan tata nilai masyarakat berupa ketentaraman.

Kata kunci: Pemberdayaan masyarakat, wirausaha, Budidaya Ikan Lele Sangkuriang

\section{PENDAHULUAN}

Kabupaten Deli Serdang yang memiliki keanekaragaman sumber daya alamnya yang besar sehingga merupakan daerah yang memiliki peluang investasi cukup menjanjikan. Menurut hasil survei 2015 dari Badan Pusat Statistik Kabupaten Deli Serdang Dilihat dari kelompok umur, persentase penduduk usia 0-14 tahun sebesar 30,60 persen, 15-64 tahun sebesar 66,07 persen dan usia 65 tahun ke atas sebesar 3,33 persen yang berarti jumlah penduduk usia produktif lebih besar dibandingkan penduduk usia non produktif. Pada kondisi 2015, di Kabupaten Deli Serdang terdapat 865.897 penduduk angkatan kerja, yang terdiri dari 810.620 jiwa (93,61 persen) terkategori bekerja dan sebesar 55.277 jiwa (6,4 persen) terkategori mencari kerja dan tidak bekerja (pengangguran terbuka). Pertumbuhan tenaga kerja yang kurang diimbangi dengan pertumbuhan lapangan kerja akan menyebabkan tingkat kesempatan kerja cenderung menurun (Badan Pusat Statistik, 2017).

Pengukuran pembangunan manusia di Kecamatan Patumbak difokuskan pada tiga dimensi yang dianggap esensial bagi kehidupan manusia yaitu: Usia hidup (longevity) dengan indikator angka harapan hidup, Pengetahuan atau (knowledge) menggunakan dua indikator yaitu angka harapan lama sekolah dan rata-rata lama sekolah, standar hidup layak (decent living standard) dengan indikator dasar rata-rata pengeluaran perkapita yang disesuaikan, perkembangan indeks pembangunan manusia (IPM) yang mencerminkan capaian kemajuan di bidang pendidikan, kesehatan dan ekonomi. Angka IPM Deli Serdang mengalami peningkatan dari 71,98 pada tahun 2015 menjadi 72,79 pada tahun 2016. (Badan Pusat Statistik, 2017a).

Agar indikator harapan hidup masyarakat pada tingkat knowledge dan decent living standar, maka perguruan harus berperan aktif dalam melakukan pemberdayaan masyarakat yang berkesinambungan sebagai aplikasi dari pelaksanaan Tri Dharma Perguruan Tinggi, yaitu Pengabdian kepada masyarakat, diman perguruan tinggi dituntut untuk berperan aktif membangun peradaban masyarakat yang mandiri, hal ini sejalan dengan pemikiran (Dariah, 2009) bahwa pemberdayaan bagian dari motivasi untuk menumbuhkan kemampuan dan keberanian masyarakat dalam menghadapi kehidupan, dan sebagai upaya untuk memperkuat kemajuan, kemandirian dan kesejahteraan berkelanjutan.

Pemberberdayaan di Pedesaan adalah langkah yang strategis dalam meningkatkan perekonomian masyarakat dalam menyediakan lapangan pekerjaan dan mengurangi kemiskinan, dengan demikian upaya pemberdayaan masyarakat harus terencana dan sistematis, salah satu upaya pemberdayaan masyarkat yang akan laksanakan melalui program kemitraan masyarakat ini adalah menciptakan kelompok masyarakat menjadi wirausaha, demikian yang dinyatakan Barus, (2013) untuk membangkitkan karakter wirausaha pada masyarakat Indonesia merupakan solusi yang yang pas dilakukan, agar masyarakat dapat bersaing dengan bangsa lain dalam menghadapi Ekonomi Asean. 
Muhammad Irfan Nasution, Muhammad Andi Prayogi, Jufrizen.

Pemberdayaan masyarakat desa melalui pencitaan wirausaha Budidaya ikan Lele menjadi pilihan pada pelaksanaan Program Kemitraan Masyarakat dikarenakan usaha budidaya lele, karena usaha ini tidak memerlukan lahan yang besar, karena akan memanfaatkan lahan pekarangan milik warga, kemudian Ikan lele merupakan salah satu ikan yang sudah dibudidayakan dan di komersilkan oleh warga. Budidaya ikan lele baik pembenihan dan pembesaran dapat dilakukan di kolam tanah, bak tembok, atau kolam terpal dan dapat memanfaatkan lahan pekarangan yang kosong (Puddin, dkk, 2015; Negara \& Pebriani, 2016); (Nasution \& Prayogi, 2018). Hasil penelitian (Rosalina, 2014), kolam terpal merupakans satu usaha dan upaya yang dapat dilakukan untuk pembenihan dan pembesaran ikan lele untuk memenuhi permintaan dan mempermudah masyarakat mendapatkan ikan lelel yang berkualitas dengan harga yang terjangkau.

Lokasi pengabdian masyarakat melalui Program Kemitraan Masyarakat di Desa Marindal II Kecamatan Patumbak Kabupaten Deli serdang Sumatera Utara berbatasa dnegan Kota Medan, memiliki lahan kosong yang potensial untuk dimanfaatkan, survey team PKM di lokasi dan menemukan masalah-masalah yang harus diselesaikan, masyarakakt yang tergabung dalam Kelompok Masyarakat (Kommpak) memiliki potensi untuk dikembangkan sehingga kelompok masyarakat ini bisa bertahan hidup dan dapat memberikan manfaat kepada masyarakat sekitar, Tim PKM menemukan beberapa masalah diantaranya 1) Masyarakat tidak pernah mendapatkan pembinaaan dari Perguruan Tinggi, 2) Kelompok masyarakat tidak pernah mendapatkan bantuan modal atau usaha dari pihak manapun, 3) Kelompok masyarakat masih sangat minim pengetahuan tentang kewirausahaan, 4) masih banyak lahan kosong milik warga yang tidak termanfaatkan, 5) tidak memiliki pekerjaan atau usaha yang dapat menopang kehidupan keluarga. Sehingga atas dasar kesepakatan dan melihat potensi yang ada pada kelompok masyarakat dan potensi desa maka maka kelompok masyarakat melalui program Kemitraan masyarakat ini akan didirikan suatu usaha yaitu Budidaya Ikan Lele di Kolam terpal, salah satu literatur yang dikatakan oleh (Rosalina, 2014) bahwa kolam terpal memiliki keunggulan seperti mudah dibuat, suhu kolam lebih stabil dibandingkan dengan kolam semen, biaya juga relative lebih murah, keterbatasan lahan tidak menjadi masalah, kondisi air yang relative lebih bersih.

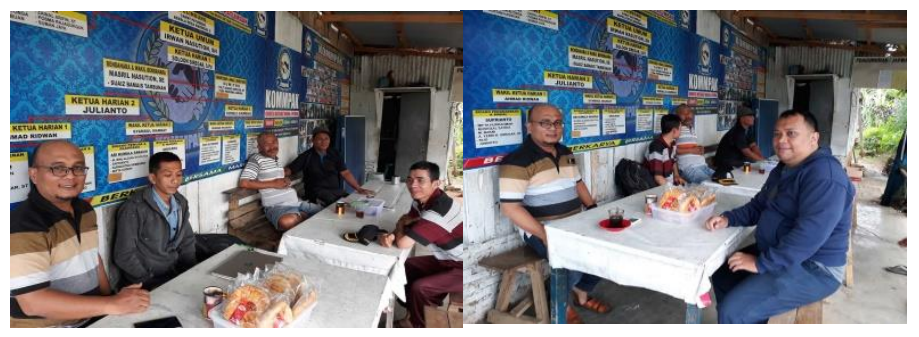

Observasi \& Identifikasi Lapangan dengan Mitra PKM 


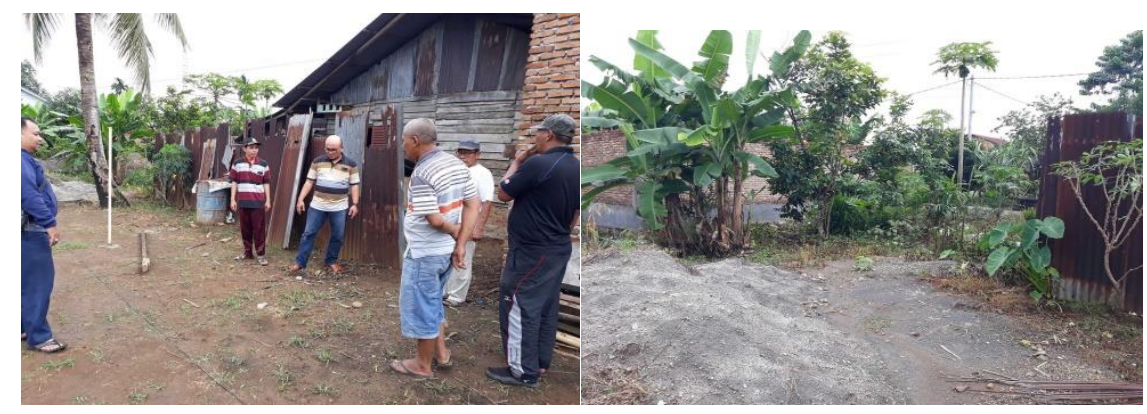

Lahan Kosong pekarangan warga yang tidak dimanfaatkan oleh warga: Lahan yang akan dijadikan Lokasi kolam terpal Ikan Lele.

Permberdayaan masyarakat perlu di fasilitasi, melalui partisipasi aktif agar mencapai tujuan dan sasaran utama yaitu memberdayakan masyarakat yang lemah dan tidak memiliki daya dan upaya agar menjadi produktif, sehingga dapat mencapai tujuan akhir dari proses pemberdayaan masyarakat yaitu masyarakat dapat meningkatkan taraf perekonomian keluarga dan mengoptimalkan sumber daya yang dimiliki oleh masyarakat (Widjajanti, 2011).

Usaha yang akan diimplentasikan melalui PKM ini sangat menarik karena dapat menciptakan kelompok wirausaha baru di tengah-tengah kehidupan masyarakat Desa yang dapat menjadi "brand image" Desa wirausaha, agar penduduk desa lebih berkreativitas, seperti yang dinyatakan dalam paper Ali \& Sari, (2013) bahwa mengasah kreativitas sangat diperlukan karena pentingnya bagi keberhasilan kita, semua aspek kehidupan akan memerlukan kemampuan kreativitas untuk mengatasi masalah dan mendapatkan ide-ide yang memperbaiki karir, bisnis, dan hidupnya, kreativitas menjaga gairah hidup dan kreativitas menjadikan hidup terus melaju.

Didorong oleh keingingan yang kuat dari masyarakat Desa Marendal II, untuk membantuk pemerintah dalam mengentaskan kemiskinan, dan menekan angka pengangguran, maka dirikan sebuah organisasi desa, dengan membentuk kelompok masyarakat tani yang bernama Kommpakk. Kelompok ini berperan aktif dalam membangun Desa Marendal II, baik dari segi perkebunan, peternakan, perikanan, yang terkoordinasi dengan Kepada Desa Marendal II.

Kelompok masyarakat ini membuat beberapa agenda kerja sebagai acuan dari program kerja yang lebih terarah agar visi dan misi tercapai salah satunya adalah menciptakan usaha produktif milik warga yang dikelola secara profesional untuk membantu masyarakat yang membutuhkan bantuan dari kelompok ini. Kelompok ini juga berusaha untuk tertib secara administrasi baik pembukuan mapun keuangan dalam mengelola keuangan organisasi, Kelompok ini memiliki Sumber Daya Manusia yang bisa diandalkan dalam mengerakkan roda organisasi secara utuh, dan memiliki visi dan misi kedepan untuk mencerdaskan masyarakat Desa Marendal II. Keanggotaan kelompok masyarakat ini rata-rata adalah sudah tidak memiliki pekerjaan yang tetap, ada yang berjualan, pensiunan dari perusahan, petani, dan pengangguran, hanya rasa saling kebersamaan dalam membangun desa Marendal II mereka bersatu dan berupaya untuk menciptakan lapangan pekerjaan bagi anggota masyarakat. 
Muhammad Irfan Nasution, Muhammad Andi Prayogi, Jufrizen.

Kelompok masyarakat yang menjadi mitra dari Program Kemitraan masyarakat ini sudah sangat dirasakan manfaat oleh masyarakat sekitar sehingga sangat disayangkan jika keberadaan kelompok masyarakat ini mati suri karena tidak ada aktivitas yang dapat membantu masyarakat, kelompok masyarakat ini sudah melakukan banyak aktivitas yang membantu masyarakat Desa Marindal II, sebagai kegiatan sosial, tetapi belum pernah melakukan kegiatan kewirausahaan. Maka dengan keberadaan PKM ini diharapkan kelompok masyarakat ini bisa menciptakan Desa wirausaha.

Observasi dan kunjungan ke lokasi Mitra, bahwa tim PKM UMSU sangat membutuhkan usaha yang produktif untuk meningkatkan pendapatan dan mengurangi angka pengangguran di Desa Marendal II. Kelompok masyarakat ini sangat membutuhkan keterampilan dan keahlian serta usaha, mereka berhasrat kuat untuk menjadi wirausaha tetapi mengetahui usaha apa yang akan dibuat dan mereka berpikir usaha tersebut selalu membutuhkan modal yang besar itulah yang masih tertanam dalam mindset para masyarakat di Desa Marendal II.

Hasil Diskusi dan kesepakatan bersama dengan kelompok Mitra calon wirausaha, maka permasalahan utama yang Mitra hadapi yaitu: 1) Masyarakat tidak pernah mendapatkan pembinaaan dari Perguruan Tinggi, 2) Kelompok masyarakat tidak pernah mendapatkan bantuan modal atau usaha dari pihak manapun, 3) Kelompok masyarakat masih sangat minim pengetahuan tentang kewirausahaan, 4) masih banyak lahan kosong milik warga yang tidak termanfaatkan, 5) tidak memiliki pekerjaan atau usaha yang dapat menopang kehidupan keluarga, 5) kelompok masyarakat Mitra sudah diatas usia produktif sehingga sulit untuk mendapatkan pekerjaan. 6) Belum memiliki kepercayaan diri untuk menjadi wirausaha.

\section{METODE}

Tahapan Kegiatan Program Kemitraan Masyarakat diantaranya: 1). Tahap Persiapan/Observasi, Observasi merupakan langkah awal kegiatan yang harus dilakukan, untuk bahan masukan dan memenuhi data yang diperlukan sebagai tindak lanjut PKM, 2). Survei dan identifakasi lokasi kegiatan, Tim melakukan survey di Jalan Nusa Indah Desa Marindal II, Kec. Patumbak, Kab. Deli Serdang Pada tahap ini, dengan menganalisis permasalahan masyarakat sebagai bagian dari perencanaan kegiatan. 3). Melakukan analisis untuk mengembangkan potensi serta mengatasi permasalahan yang muncul, untuk dilakukan Rehabilitasi dan Perbaikan, dengan cara Focuss Group Discussion (FGD), 4). Monitoring dan Evaluasi, dilakukan sebagai upaya untuk memperoleh masukkan apakah program kegiatan yang sudah dilakukan terus berjalan dengan baik dan berkesinambungan serta ditindaklanjuti oleh masyarakat. PKM dilaksanakan dengan metode pendekatan Participatory, untuk menyerap partisipasi aktif dari Mitra, dapat diukur dari keinginan dan semangat Mitrad yang ingin berwirausaha. Community Empowerment, dengan melibatkan Mitra secara aktif dari mulai tahap observasi, analisis, perencanaan, pembinaan dan pendampingan secara kontiniu, guna memperoleh saran dan masukan untuk keberhasilan kegiatan seperti yang diharapkan. Akhirny dari kegiagan ini akan dilakukan evaluasi. 


\section{HASIL DAN PEMBAHASAN}

\section{Hasil yang diperoleh dari Program Kemitraan Masyarakat ini adalah :}

\section{Aspek Produksi}

1) Pengadaan peralatan produksi untuk mendukung proses produksi budidaya ikan lele bioflok dengan Mitra, antara lain :

1. Kolam Bioflok Ukuran diameter 3 meter dengan kapasitas 5000 benih ikan lele sangkuriang

2. Kolam Biflok dengan ukuran 3x 2 meter untuk pensortiran dan pembesaran ikan lele sangkuriang.

3. Pakan ternak $360 \mathrm{Kg}$

4. Aerator, sebagai oksigen dari kolam bioflok.

5. Pendampingan budiya ikan lele sangkuriang bekerjasama dengan usaha budidaya ikan lele yang telah sukses terlebih dahulu.

\section{Aspek Pemasaran dan Keuangan}

1) Berdiskusi dengan Mitra untuk pemasaran, bertujuan untuk memberikan wawasan dan pemahaman tentang upaya yang harus dilakukan untuk pemasaran ikan lele sangkuriang.

2) Pelatihan Manajemen Keuangan bertujuan untuk membuat mitra agar transparan dalam mengelola keuangan.
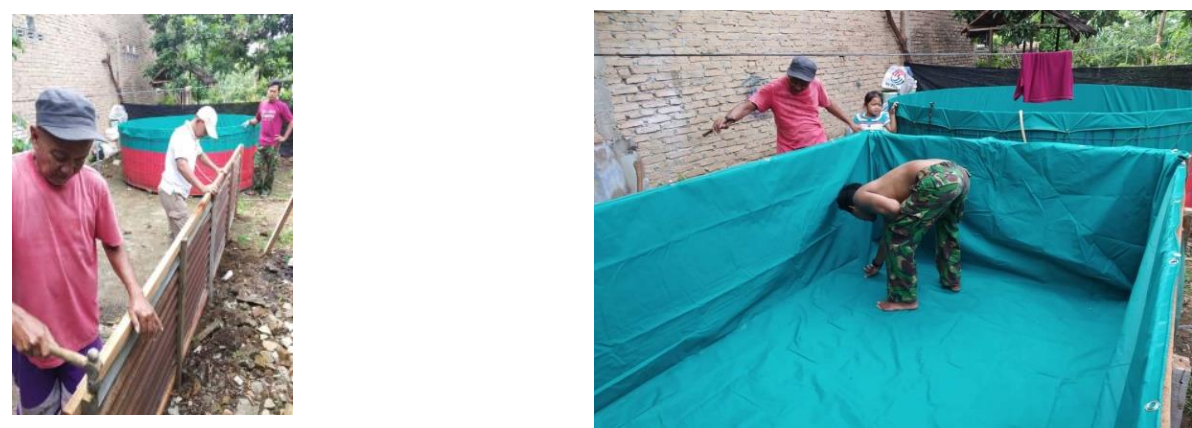

Proses Pembuatan Kolam bersama kelompok mitra
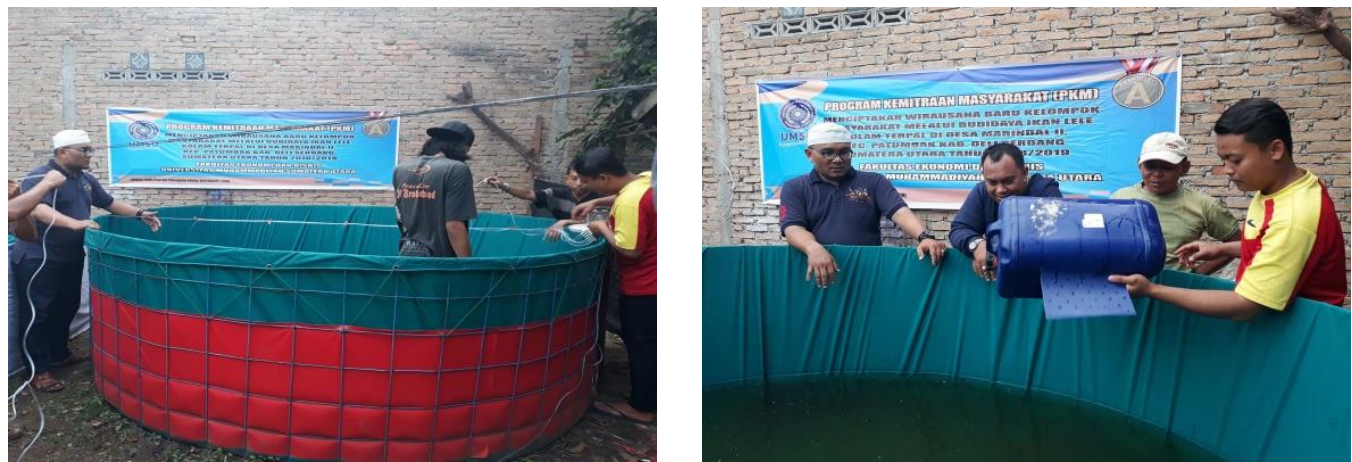

Penebaran benih ikan lele sangkuriang 
Muhammad Irfan Nasution, Muhammad Andi Prayogi, Jufrizen.

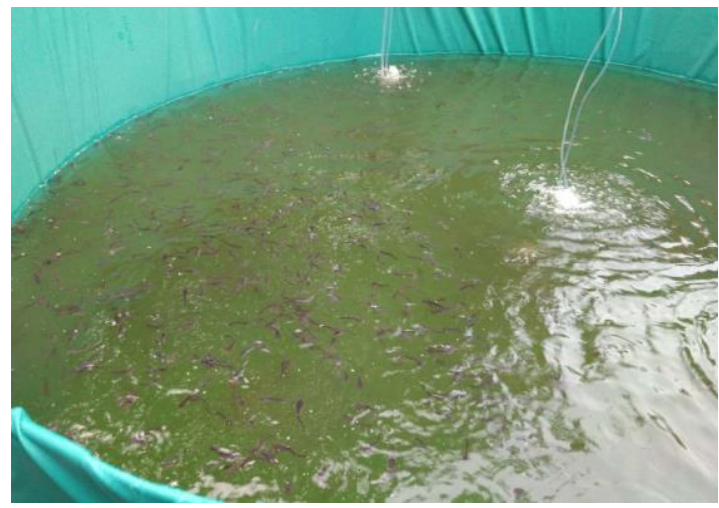

Benih Ikan Lele Sangkuriang siap untuk pembesaran

Partisipasi Mitra Dalam Pelaksanaan Programm adalah, Menyiapkan lahan yang kosong untuk membangun kolam ikan lele, Menyiapkan sumber daya untuk mengelola Budidaya Ikan Lele yang berkesinambungan, Mitra mengkuti akan seluruh rangkaian kegiatan dalam pelaksanaan kegiatan pengabdian sehingga apa yang dilakukan tim PKM, Mitra mau melakukan sesuai dengan kebutuhan usaha mitra.

Target program kemitraan masyarakat yang dilaksanakan telah terpenuhi sesuai dengan proposal yang diajukan pengusul, diantara target tersebut adalah:

Tabel 1. Hasil Kegiatan

\begin{tabular}{|c|c|c|c|}
\hline No & Aspek Kegiatan & Target Luaran & Spesifikasi \\
\hline 1. & $\begin{array}{ll}\text { Pembuatan } & \text { Kolam } \\
\text { Terpal } & \end{array}$ & $\begin{array}{l}\text { Kolam Bioflok } \\
\text { Diamter } 3 \text { meter dan } \\
\text { Kolam Terpal ukuran } \\
\text { 3x2 meter } \\
(2 \text { kolam) }\end{array}$ & $\begin{array}{l}\text { Pengadaan peralatan } \\
\text { produksi sebagai modal } \\
\text { awal berwirausaha, kolam } \\
\text { terpal, besi, kayu, seng, } \\
\text { Aerator, selang, pakan ikan }\end{array}$ \\
\hline 2. & $\begin{array}{l}\text { Benih ikan Lele } \\
\text { Sangkuriang }\end{array}$ & $\begin{array}{l}4500 \text { benih ikan lele } \\
\text { sangkuriang }\end{array}$ & $\begin{array}{l}\text { Pengadaan plankton, } \\
\text { sebagai bahan pakan alami, } \\
\text { pangan ikan. }\end{array}$ \\
\hline 3. & $\begin{array}{l}\text { Pelatihan Manajemen } \\
\text { Kuangan }\end{array}$ & $\begin{array}{ll}\text { Papan } & \text { Keuangan } \\
\text { transparan } & \\
\end{array}$ & Papan Whiteboard \\
\hline 4. & $\begin{array}{l}\text { Pelatihan pengelolaan } \\
\text { Budidaya Ikan Lele }\end{array}$ & $\begin{array}{lr}\text { Mitra } & \text { Dapat } \\
\text { mengelola } & \text { budidaya } \\
\text { ikan lele } & \text { secara } \\
\text { mandiri } & \\
\end{array}$ & Bekerjsama dengan \\
\hline
\end{tabular}

Keterampilan Mitra, tercapainya fasilitasi dalam rangka peningkatan kualitas kelompok masyarakat melalui wirausaha baru, maka mitra akan memiliki keterampilan seperti keterampilan mengelola ikan lele, dan terlaksananya program PKM. Perbaikan kondisi masyarakat yang tidak mempunyai keterampilan menjadi mempunyai 
keterampilan yang menjadikan cikal bakal untuk menjadi wirausaha dan mengurangi pengangguran, tolak ukurnya adalah mendirikan unit usaha budidaya ikan lele.

Budidaya ikan lele memiliki prospek yang sangat baik untuk dikembangkan di masyarakat, disamping memiliki daging ikan yang lezat dan perawatannya pun tidak sulit, salah satu prospek yang bisa dihasilkan ikan lele mulai dari pembenihan, pembesaran sampai kepada pengolahan ikan lele menjadi sebuah produk. Permintaan ikan lele semakin hari semakin meningkat, karena hamper semua warung makan, restoran, menyajikan ikan lele sebagai salah satu menu, maka permintaan ikan ini tidak pernah surut, disamping penawaran harga jual ikan lele juga memberikan ketertarikan, harga dipasaran ikan lele sangkuriang berkisar Rp. 20.000 sampai dengan 25.000,- per $\mathrm{Kg}$.

Data Dinas Perikanan dan Kelautan, (2018) menunjukkan bahwa 14,456.15 ton Produksi Perikanan Budidaya Kabupaten Deli Serdang Berdasarkan Jenis Komoditas Ikan Tahun 2017 dibandingkan dengan Ikan Mas dan Nila sebesar 16,597. Jumlah Ikan Yang Ada di Pasar Tradisional (Pasa Lokal) di kabupaten Deli Serdang sebanyak 1636 ton, sedangkan jumlah ikan yang berasal dari Deli Serdang yang berada di Pasar luar daerah sebanyak 67,067.93 ton, sehingga ikan yang ada di Deli serdangk lebih banyak dikirim keluar, ini menunjukkan bahwa potensi budidaya ikan lele masih terbuka lebar untuk meraih pasar-pasar tradisional yang ada di Sumatera Utara. Unit Pembenihan Rakyat (UPR) Air Tawar di Kecamatan Patumbak menurut data yang ada hanya berkisar $353 \mathrm{M}^{2}$ lahan yang termanfaatkan untuk pembenihan ikan air tawar, ini menunjukkan bahwa budidaya ikan lele belum menunjukkan menjadi usaha pilihan warga dalam meningkatkan pendapatan, sehingga masih berpeluang untuk ditingkatkan penggunaan lahan kosong yang dimiliki oleh warga. Potensi usaha Mitra dapat lihat dari analisi SWOT berikut:

Strenght (Kekuatan): Lahan yang tersedia, sumber daya manusia yang tersedia, memilik pemasaran yang luas dan mudah dipasarkan pada saat panen. Weaknesses (kelemahan): Tidak memiliki kemampun dalam mengelola usaha, Mitra belum menguasai pemasaran, tidak memiliki modal, harus sering dilakukan perawatan kolam ikan agar tidak banyak bakteri. Opportunities (peluang) : Ikan lele mudah dipelihara, ikan lele sudah dikenal dipasar, memiliki pasar yang luas, pasar tradisional, kolam pancing, rumah makan, cafe, sistem bertahan hidup ikan lelel cukup tinggi, waktu panen hanya 3 bulan. Treats (ancaman): usaha yang baru, sehingga banyak pesaing, harga pakan tidak stabil, banyak yang sudah membudiyakan ikan lele.

Permintaan konsumen akan keberadaan ikan lele semakin meningkat. Dengan teknik pemeliharaan yang baik, maka akan diperoleh hasil budidaya yang memuaskan dan diminati konsumen. Kualitas dari pembesaran ikan lele sangat ditentukan oleh bibit yang berkualitas, agar menghasilkan ikan yang layak untuk dijual dan dikonsumsi, Pemilihan benih ikan lele akan menjadi salah satu pilihan utama dan akan dibeli dari pembenihan yang sudah berpengalaman dan terbukti menghasilkan ikan yang berkualitas, agar mengasilkan ikan lele yang berkualitas, maka beberapa hal yang perlu dipersiapkan dari segi produksi: 1) Menyiapkan kolam Budidaya Ikan Lele, kolam yang digunakan diatas lahan kosong yang tidak termanfaatkan menggunakan kolam terpal, 2) kolam terpal tersebut di isi air yang ideal adalah $100-120 \mathrm{~cm}$ pengisian 
Muhammad Irfan Nasution, Muhammad Andi Prayogi, Jufrizen.

dilakukan secara bertahap, dan dibiarkan selama satu minggu, 3) menaburkan benih ikan lele pada kolam terpal, 4) pemberian pakan ikan dan pakan tambahan.

Aspek manajemen, kedua mitra belum memiliki pengetahuan bagaimana cara mengelola usaha mulai dari perencanaan, pengorganisasian, pengendalian, dan pengawasan serta dalam proses pemilihan bahan baku, proses produksi, promosi, manajemen kuangan usaha sampai kepada penentuan harga pokok produksi dan penjualan, serta pemasaran atau promosi yang akan dilakukan. Kualitas perlu diikuti dengan peningkatan penegatahuan manajemen usaha dan pemasaran antara lain, pelatihan manajemen usaha, pembukuan dan keuangan, pembuatan desain kemasan, teknik penjualan, teknik pemasaran. Usaha yang akan dirintis tentunya punya prospek masa depakan, artinya usaha bisa berlanjut dengan menguasai manajemen usaha sehingga usaha yang baru dirintis tidak runtuh karena telah dibekali dengan pengetahuan manajemen usaha yang baik terlebih lagi dengan mengelola keuangan usaha.

Dilihat dari keberadaaan sumber daya kedua mitra sudah sangat memadai, Hasil interview dan observasi dengan Mitra, mereka mempunyai niat dan tekad yang kuat untuk menjadi wirauusaha hanya saja tidak ada fasiltitator yang melakukan pembinaan dan pendampingan kepada Mitra. Mitra siap untuk menjadi wirausaha baru apabila ada yang melakukan pembinaan dan pendampingan terhadap keberadaan Mitra. Untuk itulah pelaksanaan PKM ini menjadi salah satu solusi terbaik demi terwujudnya calon usaha baru di masyarakat Desa. Keberadaan Tim pelaksana PKM juga mempunyai kualitas dan kapabalitas dalam melaksanakan kegiatan ini dan mempunyai kompetensi dalam melakukan pembinaan dan pembimbingan untuk menciptakan kedua Mitra menjadi wirausaha baru yang akan berdampak kepada kesejahteraan dan peningkatan ekonomi Mitra.

Evaluasi sebagai proses menilai sesuatu berdasarkan kriteria atau tujuan yang telah ditetapkan, kemudian diambil keputusan atas obyek yang dievaluasi. Untuk mengetahui apakah hasil dari PKM berhasil atau tidak maka perlu dilakukan proses evluasi berkelanjutan, apabila terdapat kekurangan dalam pelaksanaan kegiatan maka akan dilakukan perbaikan-perbaikan dalam pelaksanaan, setelah aktivitas evaluasi menyeluruh maka Desa tersebut akan menjadi desa binaan Universitas Muhammadiyah Sumatera Utara, yang akan lebih dikembangkan lagi pada tahap-tahap berikutnya.

\section{PENUTUP}

Program Kemitraan Masyarakat (PKM) yang dilaksanakan di Desa Marindal II Kec. Patumbak, Kab. Deli Serdang tentunya telah tercipta wirausaha ditengah-tengah masyarakat, sehingga bisa meningkatkan taraf perekonomian desa. Pemberdayaan masyarakat menjadi kelompok usaha dalam menciptakan wirausaha Budidaya ikan lele sangkuriang hanya memanfaatkan lahan kosong yang tidak terpakai menjadi berdaya guna dengan sistem bioflok yang dapat mengsfisensikan biaya. Program pengabdian masyarakat ini juga mengajarkan kepada masyarakat bahwa menciptakan wirausaha tidak memerlukan modal yang besar, hanya keberanian, tekad dan kerjasama. Pelaksanaan Program Kemitraan Masyarakat ini dapat terus berlanjut pada masa mendatang. Kegiatan budidaya ikan lele sangkuriang ini akan terus dilaksanakan dalam 
pengembangan sehingga warga dapat mandiri mengelola usaha, PKM ini jangan sampai terhenti sampai disini tetapi dapat dilanjutkan pada kegiatan berikutnya.

\section{Ucapan Terima Kasih}

Terima kasih kepada Pimpinan Universitas, Pimpinan Fakultas yang telah memberikan dukungan penuh kepada Tim Pengabdian untuk dapat melaksanakan kegiatan pengabdian masyarakat sebagai wujud tri dharma perguruan tinggi.

\section{DAFTAR PUSTAKA}

Ali, M., \& Sari, D. O. (2013). Pelatihan Kerajinan Tangan Dari Kain Flanel Sebagai Pemberdayaan. Jurnal Inovasi Dan Kewirausahaan, 2(2), 136-139.

Barus, D. P. (2013). Menumbuhkan Karakter Wiraswasta Masyarakat Indonesia Dalam Menghadapi Masyarakat Ekonomi Asean. In The 1st Education and Language International Conference Proceedings Center for International Language Development of Unissula (pp. 212-220).

Dariah, A. R. (2009). Peran Perguruan Tinggi dalam Aplikasi Variasi Model Pemberdayaan Masyarakat Desa di Jawa Barat. Mimbar, 27(2), 143-151.

Nasution, M. I., \& Prayogi, M. A. (2018). Pemberdayaan Masyarakat Dan Penerapan Teknologi Budidaya Ikan Lele Sebagai Usaha Warga Masyarakat Kota Binjai. Khadimul Ummah: Journal of Social Dedication, 2(1), 17-23.

Negara, I. K. ., \& Pebriani, D. A. . (2016). Manajemen Pembesaran Lele Dumbo Clarias Sp. Melalui Inovasi Kolam Terpal Di Desa Pakisan Kabupaten Buleleng. In Seminar Nasional Sains dan Teknologi (Senastek) (pp. 38-43). Bali. Retrieved from http://www.samakia.aperiki.ac.id/index.php/JSAPI/article/view/128

Perikanan, D. K. dan. (2018). Produksi Perikanan Budidaya Per Desa Kecamatan Patumbak Tahun 2018. Retrieved January 3, 2019, from https://diskanla.deliserdangkab.go.id/perikanan/statistik/?id=110

Puddin, K., Restuati, M., \& Siregar, Z. (2015). IbM Kelompok Usaha Budidaya Lele Organik Desa Aras Kabupaten Batu Bara. Jurnal Pengabdian Kepada Masyarakat (JPKM), 21(81), 1-12. Retrieved from http://download.portalgaruda.org/article.php?article=423439\&val=8274\&title $=\mathrm{Ib}$ M Kelompok Usaha Budidaya Lele Organik Desa Aras Kabupaten Batu Bara

Rosalina, D. (2014). Analisis Kelayakan Usaha Budidaya Ikan Lele di Kolam Terpal di Desa Namang Kabupaten Bangka Tengah. Maspari Journal, 6(1), 20-24.

Statistik, B. P. (2017a). Indeks Pembangunan Manusia Kabupaten Deli Serdang 2017. Deli Serdang: Badan Pusat Statistik Kabupaten Deli Serdang.

Statistik, B. P. (2017b). Kecamatan Patumbak Dalam Angka 2017. Deli Serdang: Badan Pusat Statistik Kabupaten Deli Serdang.

Widjajanti, K. (2011). Model Pemberdayaan Masyarakat. Jurnal Ekonomi Pembangunan, 12(1), 15-27. 